6. Старожилов В.Т. Ландшафтное районирование Приморского края. Вестник Дальневосточного отделения Российской академии наук. 2010. № 3 (151). С. 107-112.

7. Старожилов В.Т., Леоненко А.В., Крупская Л.Т., Дербенцева А.М. Геоэкология минеральносырьевого природопользования ландшафтов юга Дальнего Востока./ Министерство образования и науки Российской Федерации, Федеральное агентство по образованию, Дальневосточное отделение Российской академии наук, Институт горного дела, Дальневосточный федеральный университет. Владивосток, 2009.

8. Старожилов В. Т. Геодинамическая эволюция зон перехода северо-востока Азии к Тихоокеанской плите / В. Т. Старожилов // Гидрометеорологические и географические исследования на Дальнем Востоке: материалы 5-й юбилейной научн. конф. «К всемирным дням воды и метеорологии». Владивосток, 2004. - С.85-88.

9. Старожилов В.Т. Ландшафтные геосистемы Сахалинского звена окраинно-континентального ландшафтного пояса Тихоокеанской России // Проблемы региональной экологии. - 2016. - № 5. C. 53-57.

10. Старожилов В.Т. Эколого-ландшафтный подход к промышленным территориям юга Дальнего Востока // В сборнике: Современные геофизические и географические исследования на Дальнем Востоке России. материалы 9-й научной конференции, Владивосток: конференция приурочена к Всемирным дням воды и метеорологии, а также к 110-летию ДВГУ и 45-летию ГФФ. Дальневосточный государственный университет, Институт окружающей среды ; под редакцией Н. В. Шестакова. Владивосток, 2010. С. 155-158.

11. Старожилов В.Т. Проблемы ресурсопользования, структура и пространственная организация ландшафтов приокеанских Дальневосточных территорий // В сборнике: Науки о Земле и отечественное образование: история и современность. материалы Всероссийской научнопрактической конференции, посвященной памяти академика РАО А. В. Даринского. Российский государственный педагогический университет им. А. И. Герцена, факультет географии. 2007. С. 310-312.

12. Старожилов В. Т. Ландшафтные геосистемы Сахалинского звена Тихоокеанской России // В сборнике: Научная дискуссия: гуманитарные, естественные науки и технический прогресс. Материалы VII Всероссийской научно-практической конференции. 2015. С. 54-64.

\title{
Теймурзаде Л.Т.к. \\ Живетский ярус среднего девона (средне и верхнеживетский подъярусы) Нахичеванской АР и его зональное расчленение
}

Азербайджанский Государственный Университет Нефти и Промышленности (Азербайджан, Баку)

doi: 10.18411/lj-04-2021-75

\section{Аннотация}

Отложения живетского яруса широко развиты в западной части Нахичеванской Автономной Республики, они представлены в основном карбонатными породами мощными слоями известняков, часто органогенного происхождения; в верхней части довольно в большом количестве участвуют и терригенные материалы: аргиллиты, песчаники, алевролиты и кварциты. В составе живетского яруса Нахичеванской АР установлены две свиты: садаракская и арпачайская.

Садаракская свита охватывает в своем стратиграфическом объеме две брахиоподовые зоны: 1) зона Stringocephalus burtini и 2) зона Crurithyris inflatus.

В составе арпачайской свиты выделяются две брахиоподовые зоны: 1) зона Spinocyrtia subcuspidata и 2) зона Undispirifer undiferus - Emanuella pseudovolhynica.

Каждая из этих зон характеризуется своеобразным, стабильным, присущим только ей, фаунистическим комплексом, но в то же время они отличаются друг от друга различным литологическим составом.

Ключевые слова: разрез, отложения, свита, зона, ярус, фауна, горизонт, биостратиграфические зоны, подсвита. 


\section{Abstract}

Deposits of the Givetian stage are widely developed in the western part of the Nakhichevan Autonomous Republic, they are represented mainly by carbonate rocks - thick layers of limestone, often of organogenic origin; in the upper part, terrigenous materials are also quite abundant: mudstones, sandstones, siltstones, and quartzites. According to the scheme adopted by ISC Givetian stage of the region has the following local stratigraphic and zonal divisions (from bottom to top):

- There are two suites in stage composition:

Sadarak and Arpachai;

- Sadarak suite covers two brachiopod zones by its stratigraphic volume:

1) Stringocephalus burtini zone;

2) Crurithyris inflatus zone;

- There are two brachiopod zones in the Arpachai suite:

1) Spinocyrtia subcuspidata zone;

2) Undispirifer undiferus - Emanuella pseudovolhynica zone.

Moreover, each of these zones can be characterized by original, stable faunistic complex but along with it they differ from each other by various lithological composition.

Key words: section, sediments, suite, zone, , stage, fauna, horizon, biostratigraphic zones, subformation.

\section{Средне и верхнеживетский подъярусы}

Арпачайская свита (Мамедов, 1980). Принимается в объеме двух брахиоподовых зон: 1) Spinocyrtia transcaucasica и 2) Undispirifer undiferus - Emanuella pseudovolhynica и по своему возрасту отвечает среднему и верхнему живету (Gi1+Gi2). Стратотип находится в окрестности пос.Гюмушлуг на левом берегу реки Восточный Арпачай.

Зона Spinocyrtia transcaucasica (Мамедов, 1962) принимается в объеме нижнеарпачайской подсвиты. Стратотип находится на левом берегу р.Восточный Арпачай, в окрестности пос.Гюмушлуг. Нижняя граница проводится по обновлению комплекса фауны, прежде всего по появлению в разрезе вида-индекса, крупных раковин Schizophoria traversensis Grabau, Cyrtospirifer(?) aperturatus cuspidatus (Arch. et Vern.) и др., а также по изменению литологического состава, по появлению сильно песчанистых известняков, иногда переходящих в известковистые песчаники окрашенные в красноватый цвет. Распространена в бассейне р.Восточный Арпачай: в окрестности сел.Данзик (парастратотип), пос.Гюмушлуг (стратотип), на правом борту долины Яйджи-Дереси, в ее средней части, в районе сел.Садарак - немного севернее, северо-восточнее от селения и в районе низовья р.Джаанам-Дереси. Литологически представлена известняками темными, темно-серыми, обычно переполненными органическими остатками, не редко органогенными, часто песчанистыми и чередующимися с ними аргиллитами и редкими пропластками песчаников и алевролитов. Преобладают известняки.

Наиболее полно зона представлена в Данзикском и Гюмушлугском разрезах. Мощность отложений зоны transcaucasica в Гюмушлугском разрезе равна 49 м, а в Данзикском разрезе - 70 м.

Известняки и песчаники переполнены органическими остатками; они иногда встречаются в алевролитах и даже в краевых частях аргиллитов. Встречаются: брахиоподы, кораллы (ругозы и табуляты), мшанки, пелециподы, гастроподы, криноидеи и другие ископаемые организмы. Из брахиопод наиболее характерными видами для рассматриваемой зоны являются: Schizophoria traversensis Grabau, Sch. schnuri schnuri Struve, Rhipidomella polonica (Sobelev), Mendacella penelope (Hall), Schuchertella pelargonatoides Mamedov, Productella productoides sinensis (Kayser), Kransia parallelepipeda (Bronn), K. subcordiformis (Schnur), Hypothyris aff. lungtunpeensis 
(Kayser), "Camarotoechia" subsignata Reed, Desquamatia prisca gladbachensis U.Jux, D. desquamata kansuensis (Grabau), Variatrypa ventricosa (Kelus), Spinatrypa (Is.) aspera subkwangiensis (Tien), Spinatrypina (Sp.) girzenensis Copper, Indospirifer padaukpinensis (Reed) var. multicostata Dagon, I. speudowilliamsi Rzon., Cyrtospirifer aperturatus aperturatus (Schloth.), C. aperturatus cuspidatus (Arch. et Vern.), Spinocyrtia transcaucasica Mamedov, Athyris vittata (Hall), Dicamara plebeja (Sow.), D. prunulum (Schnur), Chascothyris barroisi Holz., Denckmanella ex gr. ovata M. et I.Breivel, Rensselandia caiqua (Arch. et Vern.) и многие другие. Все вышеуказанные и не указанные характерные для данной зоны виды и большинство сопровождающих видов являются сугубо живетскими видами.

В этой зоне встречены конодонты: Icriodus brevis Stauffer, I. oblinquimarginatus Bischoff et Ziegler, I. difficilis Zieg., Klapp. et Johnson (опр. В.Г.Халымбаджи). Такое сочетание комплекса отвечает средней подзоне зоны varcus, указывает В.Г.Халымбаджа.

Здесь в массовом количестве встречаются кораллы, особенно крупные одиночные ругозы. Из них определены: ругозы - Hexagonaria amanshauseri Glinski, H. boloniense Blainv., H. primitiva Sajut., Dansicophyllum conoideum Ult., D. tenuiconicum Ult., Neostringophyllum waltheri (Joh), H. heterophylloides (Frech), Macgeea araxis (Frech), M. caucasica Soshk., Disphullum paschiense (Soshk.), Heliophyllum halli E. et H., Phillipsastraea ibergenseformis Spassky, Cosjuvia rosiformis (Soshk.), Aulacophyllum armenicum Soshk., Prismatophyllum ex gr. hexagonum Joh, Tabulophyllum sp. (близкий к T. butovi Bulv.), Zmetnogorsky bublichenkoi Spassky и др.; табуляты - Thamnopora ex gr. reticulata Blainv., Th. angusta Lec., Th. cervicornis cervicornis Blainv., Th. cervicornis obtusispinosa Dubat., Th. ex gr. alta (Tschern.), Th. aff. boloniensis Goss., Caliapora ex gr. battersbyi Milne Edwards et Haime, Heliolites porosus Goldf., Crassialveolites obtortus Lec., Coenites tenella Gürich, Placocoenites cf. medius (Lec.), Alveolitella ex gr. figurata Dubat., Marisastrum sedgwicki (E.H.), Chaetetes tenuis Frech и др. Как Н.Я.Спасский и В.Н.Дубатолов, так и М.В.Ерина, А.И.Ким и О.П.Ковалевский, определившие наши образцы по кораллам в разные годы, указывают, что вышеуказанный комплекс кораллов указывает на живетский возраст вмещающих пород.

В этом интервале разреза встречены строматопораты (опр. О.В.Богоявленской): Stromatopora sp., Actinostroma cf. boreale Bogoyavl., A. fillitextum (Lec.). Как указывает О.В.Богоявленская, комплекс строматопорат определяет возраст зоны transcaucasia как верхнеживетский.

Из встреченных в зоне мшанок определены (А.Г.Пламенской): Hederella (Hederella) filiformis (Bill.), H. (Paralhederella) sp., Stereotoechus ramosus Morozova, Lioclema aff. passitabulatum Duncan, Rectifenestella mishanensis Yang. и др. Такое сочетание видов мшанок, по заключению А.Г.Пламенской, позволит определить возраст отложений рассматриваемой зоны как живет.

Из зоны transcaucasica определены остракоды (опр. К.Я.Гурьевич): Eridoconcha sp. indet., Saccarchites berdance Rozhd., Marginia sp. indet., Ochascapha sp. indet., Ortocypris subparalella (Pol.), O. cf. parilis Rozhd., Cavellina sargaeviensis Rozh. Из этого комплекса остракод, по заключению К.Я.Гурьевич, Eridoconcha sp. indet., Ortocypris subparalella - виды характерны для живетского яруса Русской платформы. Остальные виды известны из нижней части франского яруса верхнего девона Башкирии.

Рассматриваемая зона, по-видимому, соответствует сафоновскому горизонту Кузнецкого бассейна с Indospirifer pseudowilliamsi Rzon. и его стратиграфическим аналогам на западном склоне Урала (чеславская свита, - ее средняя часть, т.е. ардатовские слои), центральной и восточной частях Русской платформы, в Казахстане (айдарлинский горизонт) и на Дальнем Востоке (нижняя часть ольдойской свиты). В Арденнах, по-видимому, рассматриваемой зоне отвечают отложения среднего живета зона Spinocyrtia ascendens (слои Терpe-Аур). В Эйфельских горах с этим стратиграфическим уровнем следует сопоставить крепкие слои с Spinocyrtia mediotexta. 
Зона Undispirifer undiferus - Emanuella pseudovolhynica (Мамедов, 1962) по своему объему соответствует верхнеарпачайской подсвите. Стратотип находится на левом берегу р.Восточный Арпачай, в окрестности пос.Гюмушлуг. Кроме стратотипичного гюмушлугского разреза, отложения этой зоны распространены в районе сел.Данзик, на правом борте долины Яйджи-Дереси, в низовье р.ДжаанамДереси, в верховье долины Багарсых-Дереси и в верхней полосе Багарсыхского хребта. Нижняя граница устанавливается по обновлению фаунистического комплекса и резкому изменению литологического состава в разрезе: в зоне исчезают такие крупнослоистые и даже среднеслоистые крепкие, часто кристаллические известняки, которые имеются в подстилающей зоне, т.е. в нижнеарпачайской подсвите; здесь резко увеличивается терригенный материал, преобладают аргиллиты. Увеличивается количество алевролитовых прослоек, которые, часто уплотняясь, превращаются в тонкослоистые и тонкозернистые песчаники. Известняки становятся тонкослоистыми, некрепкими, часто детритовыми и песчанистыми. Известняки, нередко и песчаники содержат богатую фауну. Фауна встречена и в аргиллитах, мергелях и алевролитах. Верхняя граница определяется по появлению в разрезе позднедевонских представителей спириферид: Cyrtospirifer ex gr. disjunctus (Sow.), C. schelonicus Nal. и др. Общая мощность в стратотипическом гюмушлугском разрезе составляет 68,5 м, в данзикском разрезе - 73 м, а наибольшую мощность она приобретает в низовье р.Джаанам-Дереси - 128,5 м.

Зона характеризуется богатым комплексом фауны и флоры. Из брахиопод наиболее характерными видами являются: Rhipidomella vanuxemi (Hall), Protoceptostrophia perplana (Conrad), Leptaena kwangsiensis Grabau, Chonetes ex gr. bretzii Schnur, Productella productoides productoides (Murch.), P. productoides sinensis, Gypidula rectangularioformis Mam., Devonogypa granata rossica Rzon., Kransia parallelepipeda (Bronn), K. subcordiformis (Schnur), Backmannia pentagona (Kayser), Isopoma brachyptycta (Schnur), Septalaria ascendens (Steininger), S. phillipsii (Davidson), Pugnax acuminatus dillanus H.Schmidt, Yunnanella cf. custos H.Schmidt, Variatrypa zonata (Schnur), V. ventricosa (Kelus), Desquamatia hunanensis (Grabau), D. auriculata (Haysaka), D. circularis (Leidhold), Spinatrypa (Isospinatrypa) aff. rockfordensis (Fenton et Fenton), Sp. (Invertrypa) nana (Khalfin), Spinatrypina (Sp.) girzenensis Copper, Indospirifer chaui (Grabau), Spinocyrtia aff. mediotexta (Arch. et Vern.), Mucrospirifer cf. cooperi Wright et Wright, Cyrtina heteroclita Defrance, C. multiplicata Davidson, Allanella ex gr. allani Warren, Undispirifer undiferus undiferus (Roemer), U. undiferus several (Davidson), Emanuella pseudovolhynica Mamedov, Athyris(?) complanatus (Schloth.), Dicamara plebeia (Sow.), Rensselandia cf. circularis (Holz.) и др.

Из большого списка брахиоподовой фауны всего две формы известны из верхнего девона. Это - Pugnax acuminatus dillanus, установлена Г.Шмидт (H.Schmidt, 1941) из верхнего девона Германии (Adorf-Stufe, Iberge kalk). Типичный Spinatrypa (Is.) rockfordensis (Fenton et Fenton) встречается в низах франского яруса Канады. Cyrtospirifer lonsdalii (Murch.) в Бельгии встречается в верхах живетского яруса и переходит в низы франского яруса. Ряд видов из списка встречаются здесь не только в живетских отложениях, но и в верхах эйфельского яруса: Douvillina (D.) interstrialis (Phill.), Radiomena irregularis (Roemer), Kransia parallelepipeda (Bronn), Backmannia pentagona (Kayser), Variatrypa zonata (Schnur), Spinospirifer diluvianoides Biernat, Reticulariopsis aviceps (Kayser), Mystrophora areola (Quenstedt). А подавляющее большинство видов, встреченных в описываемой зоне, являются сугубо живетскими, они в основном встречаются в верхнеживетском подъярусе. В целом, брахиоподовый комплекс фауны определяет возраст зоны undiferus-pseudovolhynica как позднеживетский.

Из интервала зоны undiferus-pseudovolhynica определены конодонты (опр. В.Г.Халымбаджи): Icriodus difficilis Zieg., Klapp. et Johnson, I. oblinquimarginatus Bischoff et Zieg., I. sp. B Weddige, Icriodus sp., Polygnathus ex gr. varcus Stauffer, Pol. 
xylus xylus Stauffer, Eognathodus cf. bipennatus bipennatus (Bischoff et Zieg.), Ozarcodina sp. Наличие форм Polygnathus ex gr. varcus Stauffer и Icriodus sp. В (по Weddige) свидетельствует о живетском возрасте вмещающих пород. В тоже время: Icriodus oblinquimarginatus происходит из зоны ensensis и проходит через нижнюю и среднюю подзоны varcus; I. difficilis появляется с нижней подзоны varcus. Вид Eognathodus bipennatus bipennatus распространен в верхней подзоне зоны ensensis и проходит в нижнюю подзону varcus. Таким образом, такое сочетание видов конодонтового комплекса может определить возраст вмещающих пород, как средняя подзона varcus.

К аналогичному, либо к близкому выводу приводят анализы, встреченных в рассматриваемой зоне, других групп фауны. Здесь встречены ругозы: Neostringophyllum heterophylloides Frech, N. waltheri (Joh), Macgeea araxis Frech., M. gumushlugense Spassky, M. cf. caucasica Soshk., Dansicophyllum conoideum (W. et V.), Ptenophyllum butovi Bulv., Gryphophyllum isactis Frech., Hexagonaria boloniense Blainv., Aulacophyllum armenicum Soshk., A. sp. nov. Spassky, Peneckiella ex gr. darwini Frech, Pachyphyllum ibergense (A.Roemer). За исключением Pachyphyllum ibergense (A.Roemer), который в Рейнской области (ФРГ) происходит из низов франского яруса (Iberger kalk), весь комплекс ругоз, по заключению Н.Я.Спасского, имеет живетский облик, причем практически все они известны и из садаракской свиты. Следовательно, арпачайская и садаракская свиты между собой взаимосвязаны.

Из табулят в рассматриваемой зоне встречены: Thamnopora alta (Tchern.), Th. nicholsoni (Frech), Th. boloniensis Goss., Placocoenites medius medius (Lec.), Pl. medius altchedatensis Dubat., Caliapora cf. battersbyi (M.-Edw. et H.), Striatopora sp. nov. Dubat., Alveolites suborbicularis Lec., A. aff. tischnoffi Dubat., Crassialveolites crassus (Lec.), C. crassiformis Solee, C. obtortus Lec. Как видно из приведенного списка тамнопорового комплекса, многие виды табулят, встреченные в рассматриваемой зоне, известны из низов арпачайской свиты и этот комплекс, по заключению В.Н.Дубатолова, датирует возраст зоны как позднеживетский.

Из строматопорат определены (опр. О.В.Богоявленской): Parallelepora ex gr. hüpshii Barg., Stachyodes ex gr. singularis Lec., Stachyodes sp. Из них: типичный вид Р. hüpshii (Barg.), распространен в кувене (Co2b), живете и среднем фране (F2) Динанта; Stachyodes singularis Lec. известен из среднего девона Евразии.

Из мшанок здесь встречены представители рода Reteporida: R. sadarakensis Plam., sp. nov., R. sp. Род Reteporida распространен в среднем девоне Северной Америки, в живетском и франском ярусах Горного Алтая, во франском ярусе Кузбасса.

Криноидеи представлены следующими видами: Hexacrinites kartzevae Yelt. et J.Dubat., Tessarocrinus sp., Calleocrinus sp. nov. J.Dubat. et E.Zinev., Cyclocetocrinus sp. Вид H. kartzevae преимущественно распространен в верхнем живете, реже в нижнем живете и нижнем фране на Западной и Северо-Восточной окраинах Кузнецкого бассейна.

Из пелеципод, встреченных в данной зоне, в настоящее время определены два вида: Paracyclas (P.) rugosa Goldf. и Nuculuidea fornicata (Goldf.). Нахождение в рассматриваемой зоне этих видов пелеципод, свидетельствует лишь о среднедевонском возрасте вмещающих их пород отложений.

Из комплекса спор в основании зоны наиболее многочисленными и характерными являются: Archaeozonotriletes vorobjensis Naum., Arch. aff. vorobjensis Naum., Arch. violabilis Tschibr., Arch. echinatus Naum. var. microspinellosus Tschibr., Arch. comptus Naum. var. densispinosus Tschibr., Arch. repertitus Tschibr. Кроме того, встречаются в небольшом количестве множество сопровождающих видов. Все перечисленные формы, по заключению Е.В.Чибриковой и В.А.Олли, характерны для живетского яруса Русской платформы и Урала.

Описываемой зоне соответствует алчедатский горизонт Кузнецкого бассейна и его стратиграфические аналоги: на Русской платформе, возможно, верхи старооскольского горизонта (муллинские слои), верхи анхорского горизонта Средней 
Азии и верхи айдарлинского горизонта Казахстана. В Арденнах, по-видимому, рассматриваемой зоне соответствуют слои Монт-Аур с Hexagonaria quadrigemins, отвечающие верхнему живету (Gid), а в Эйфельских горах - слои Болсдорф.

\section{Схема расчленения среднего девона и верхов нижнего девона нахичеванской $A P$}

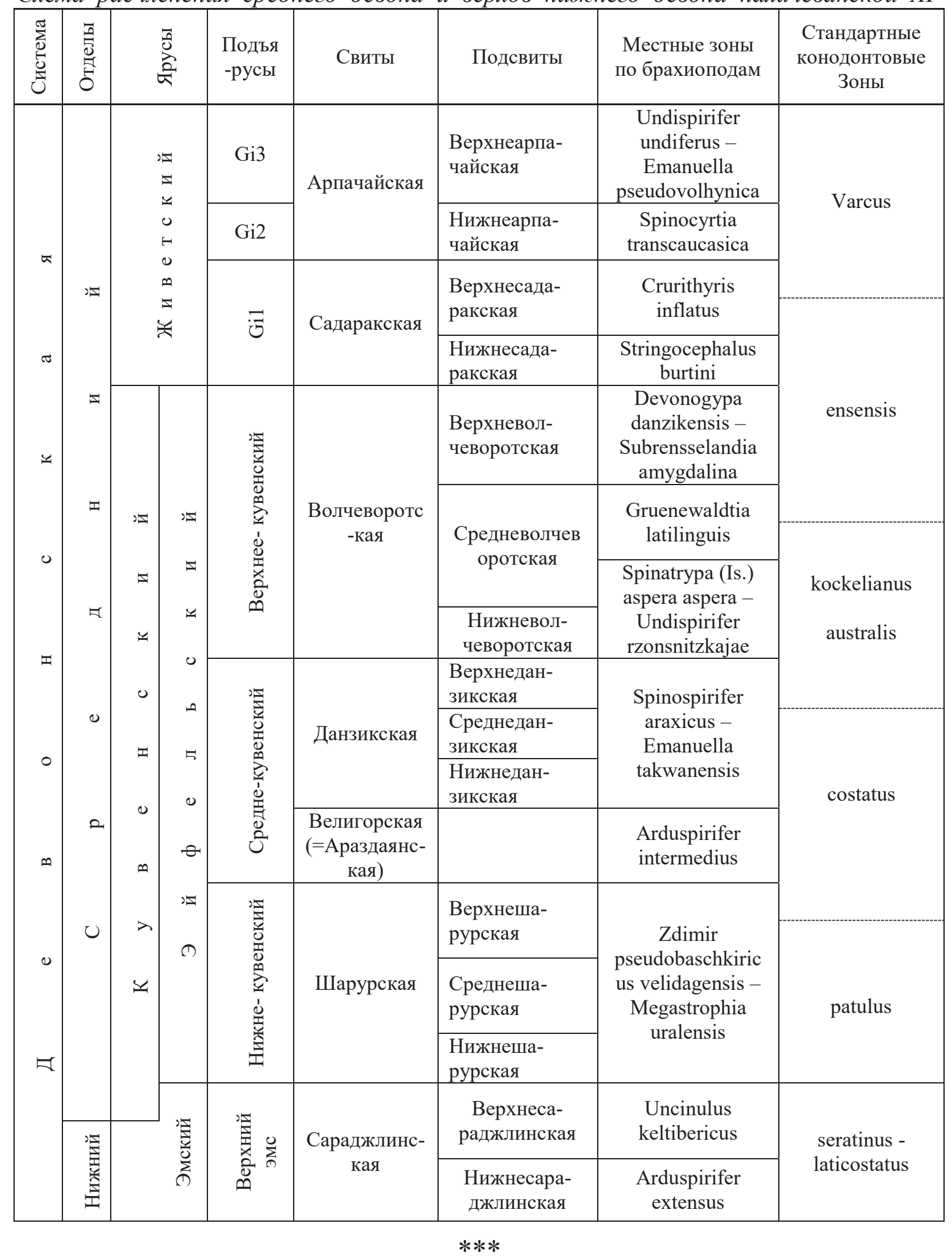

1. Богоявленская О.В. Среднедевонские строматопораты Закавказья. В кн.: Нижний ярус среднего девона на территории СССР. Тр. Ин-та геологии и геофизики СО АН СССР, вып. 562. Изд. "Наука", М., 1983, с.30-31. 
2. Гречишникова И.А., Левицкий Е.С. О некоторых спорных вопросах биостратиграфии среднего девона Нахичеванской АССР (Южное Закавказье). Изв. вузов. Геология и разведка, № 10, 1981, с.3-8.

3. Дубатолов В.Н. Зональное расчленение среднего девона Закавказья по табулятам. Тезисы докладов. Выездная сессия комиссии МСК по девонской системе в Азербайджане. Изд. "Элм", Баку, 1980, с.15-18.

4. Мамедов А.Б. Зональное расчленение эйфельского яруса среднего девона Нах.АССР. Изв. АН Азерб.ССР, серия Науки о Земле, 1979, № 5, с.92-98.

5. Мамедов А.Б. Зональное расчленение среднего девона Закавказья по брахиоподам. В кн.: Нижний ярус среднего девона на территории СССР. Изд. "Наука", М., 1983, с.112-130.

6. Мамедов А.Б. и Ржонсницкая М.А. Девонская система. В кн.: Геология Азербайджана. Том I. Стратиграфия. Ч.І. Докембрий и палеозой. Баку, 1999. Изд-во "Nafta-Press", c.19-188.

7. Пламенская А.Г. Среднедевонские мшанки Закавказья. В кн.: Нижний ярус среднего девона на территории СССР. Изд. "Наука", М., 1983, с.148-153.

8. Спасский Н.Я. Анализ распространения среднедевонских ругоз Закавказья. В кн.: Нижний ярус среднего девона на территории СССР. Изд. "Наука", М., 1983, с.164-170.

9. Frech F., Arthaber G. Uber das Palaeozoicum in Hocharmenien und Persien: Mit einem Anhang uber die Kreide von Sirab in Persien.- Beitr.Paleontol. und Geol. Ostereich $\square$ Ungars und des Orients, 1900, Bd.12, № 4, s.161-208.

10. Mamedov A.B. and Rzhonsnitskaja M.A. Devonian of the South Transcaucasus. Zonal subdivision, boundaries of series and stages, correlation. Cour. Forsch. $\square$ Inst. Senckenberg, 75: 135-156, Frankfurt a M., 1985.

\section{Jalilova L.Z., Mehdiyeva N.Z. \\ Role of the climate changez in soils salinization}

Institute of Soil Sience of Agrochemistry of ANAS

(Azerbaijan, Baku)

doi: 10.18411/lj-04-2021-76

\section{Аннотация}

В статье представлена информация о последних изменениях климата в Азербайджане. Исследования показали, что изменения климата орошаемые земли на Муганской равнине в Кура-Аразской низменности также подверглись засолению и засоленность в результате наводнений, снизилось плодородие почвы и урожаи сельскохозяйственных культур. Эти наводнения серьезно повредили площадь 70012 га, и считается целесообразным проводить мелиоративные мероприятия без учета природных условий.

Ключевые слова: климат, орошение, наводнение, плодородие, урожайность.

\section{Abstract}

The imformation about the changes occuring in the Kur-Araz valley soils has been given in the article. The investigations showed that the irrigated. Soils of the Mughan plain in the Kur-Araz valley exposed to salinization and solonetrification, the soils fertility decreased, the productivity obtaining from agricultural plants reduced as a result of the floods and mudslides. The same floods seriously damaged $70012 \mathrm{~h}$ of the zone and the meliorative measures were realized for their prevention.

Key words: climate, irrigation, flood, fertility, productivity.

At present correctly using of the soils, obtaining of higher product from agricultural plants is one of the most important problems. Now some of the plots good for arriculture aren't used or are used in a planned way in the republic. That's why the GIS technologies are used in performance of the exact soil work at present. Here the soil work makes a chance to optimize cultivation and develop agricultural crops by considering the natural, economical, technological and sosial factors[4]. 